Bài báo khoa học

\title{
Một số kết quả ban đầu về ứng dụng số liệu vệ tinh đánh giá độ cao sóng dự báo
}

\author{
Phạm Khánh Ngọc ${ }^{*}$, Nguyễn Bá Thủy ${ }^{1}$ \\ ${ }^{1}$ Trung tâm Dự báo Khí tượng thủy văn quốc gia; ngocpkchibo@gmail.com; \\ thuybanguyen@gmail.com \\ *Tác giả liên hệ: ngocpkchibo@gmail.com; Tel.: +84-375203967
}

Ban Biên tập nhận bài: 23/3/2020; Ngày phản biện xong: 16/05/2020; Ngày đăng bài: $25 / 07 / 2020$

Tóm tắt: Nâng cao chất lượng dự báo các yếu tố khí tượng thủy văn nói chung và dự báo hải văn nói riêng có vai trò quan trọng trong dự báo, cảnh báo khí tượng thủy văn phục vụ phòng, chống và giảm nhẹ thiên tai và phát triển kinh tế biển. Ở Việt Nam, do hạn chế về số liệu quan trắc khí tượng thủy văn biển nên dự báo sóng biển chủ yếu dựa trên các kết quả của mô hình số trị. Cũng chính vì thiếu số liệu quan trắc nên đánh giá kết quả dự báo của mô hình còn nhiều hạn chế, nhất là tại khu vực biển xa bờ dẫn tới sản phẩm dự báo chưa thực sự đủ độ tin cậy. Trong nghiên cứu này giới thiệu kết quả thu thập, phân tích và xử lý số liệu quan trắc sóng bằng vệ tinh và một số kết quả đánh giá dự báo sóng của mô hình SWAN trên khu vực Biển Đông. Đánh giá kết quả dự báo sóng tháng 10 năm 2020 cho thấy giữa số liệu dự báo từ mô hình và quan trắc độ cao sóng từ vệ tinh có hệ số tương quan khá lớn với sai số nhỏ ở cả thời hạn dự báo 24 và 48 giờ, ngoại trừ những ngày có bão.

Từ khóa: Dự báo sóng biển; Vệ tinh; Đánh giá dự báo.

\section{Mở đầu}

Sóng biển là yếu tố hải văn được quan tâm bậc nhất đối các hoạt động kinh tế xã hội khu vực ven biển và giao thông hàng hải. Chính vì vậy mà các bản tin cảnh báo, dự báo sóng luôn được quan tâm không chỉ trong những thời điểm có thời tiết nguy hiểm (bão, áp thấp nhiệt đới, gió mùa mạnh...) mà hàng ngày để lập kế hoạch cho các hoạt động trên biển. Ở Việt Nam do hạn chế về số liệu quan trắc nên dự báo sóng chủ yếu dựa trên kết quả của mô hình số trị. Các kết quả dự báo của mô hình SWAN được thiết lập tại Trung tâm Dự báo khí tượng thủy văn (KTTV) quốc gia là nguồn tham khảo chính để đưa ra các bản tin dự báo sóng hằng ngày tại Việt Nam. Mặc dù mô hình đã được hiệu chỉnh và kiểm định trong một vài đề tài, dự án, tuy nhiên với thời gian ngắn và không gian kiểm định còn giới hạn nên chất lượng dự báo chung chưa thực sự đủ độ tin cậy. Việt Nam có đường bờ biển trải dài trên $3200 \mathrm{~km}$, tuy nhiên, hiện tại mạng lưới trạm quan trắc khí tượng, hải văn chỉ có 26 trạm nằm dải rác ở ven bờ, một số đảo và nhà giàn, quan trắc sóng hoàn toàn được thực hiện theo ước lượng bằng mắt thường nên hạn chế cả về tần suất quan trắc và chất lượng số liệu. Chính vì vậy rất khó khăn cho công tác dự báo và đánh giá chất lượng dự báo sóng biển.

Trong lĩnh vực KTTV ở Việt Nam nghiên cứu sử dụng số liệu vệ tinh vào dự báo chủ yếu thực hiện trong dự báo khí tượng và thủy văn và yếu tố được quan tâm nhất là dữ liệu mưa ước lượng từ vệ tinh [1-4]. Trong khi đó, đối với dự báo sóng biển một số nghiên cứu chủ yếu tập trung vào phát triển và hoàn thiện công nghệ dự báo [5-6]. Tại nước ngoài, nghiên cứu sử dụng số liệu quan trắc độ cao sóng từ vệ tinh vào dự báo sóng biển đã thực hiện từ lâu nhưng 
chủ yếu tại các nước phát triển. Trong đó, số liệu quan trắc sóng từ vệ tinh được sử dụng vào 2 mục đích, đó là kiểm nghiệm các mô hình dự báo sóng và đồng hóa dữ liệu cho mô hình dự báo sóng. Hướng nghiên cứu sử dụng số liệu vệ tinh để đánh giá chất lượng mô hình dự báo ngày càng phát triển với nhiều thuật toán phân tích và sử lý số liệu được cập nhật, như trong các nghiên cứu điển hình [7-9]. Sử dụng số liệu quan trắc sóng từ vệ để đồng hóa dữ liệu đã cải thiện đáng kể chất lượng dự báo sóng, nhất là làm giảm xu thế thiên cao và thiên thấp về độ cao sóng dự báo [10-13]. Những năm gần đây, nhiều cơ quan dự báo của nước ngoài đã đưa sản quan trắc độ cao sóng từ vệ tinh cũng như kết quả đánh giá dự báo lên web site như là những báo cáo hàng tháng [14-16].

Trong khuôn khổ dự án hợp tác về chia sẻ kinh nghiệm dự báo giữa Trung tâm KTTV quốc gia và Viện Khí tượng Nauy, phía Nauy đã cung cấp cho Trung tâm Dự báo KTTV quốc gia nguồn dữ liệu quan trắc độ cao sóng bằng vệ tinh được cung cấp bởi chương trình "Dịch vụ Giám sát Môi trường Biển Copernicus - CMEMS" của Ủy ban Châu Âu [4]. Nhiều cơ quan dự báo của Châu Âu hiện nay như là Viện Khí tượng Nauy (Met Norway) đã sử dụng nguồn số liệu này để đánh mô hình dự báo sóng và cập nhật kết quả đánh giá trên website của họ [17]. Hiện tại dữ liệu quan trắc sóng được thực hiện bởi 7 vệ tinh đo cao bao gồm Jason3, Sentinel-3A, Sentinel-3B, Cryosat-2, SARAL/AltiKa, CFOSAT và Hai Yang-2B với các nhiệm vụ khác nhau. Các dữ liệu này sau đó được xử lý bởi hệ thống phân tích dữ liệu đo độ cao đa nhiệm vụ WAVE-TAC dựa trên các thuật toán với các tiêu chí nghiêm ngặt khác nhau. Các số liệu vệ tinh được cung cấp gần với thời gian thực, được cập nhật liên tục với độ phân giải không gian là $7 \mathrm{~km} \times 7 \mathrm{~km}$ [17]. Như vậy, ngoài các số liệu quan trắc theo phương pháp truyền thống thì dữ liệu vệ tinh được xem như là một nguồn dữ liệu đáng tin cậy và có thể bổ sung vào chuỗi số liệu quan trắc còn thiếu sót.

Trong bài báo này, một vài kết quả bước đầu trong việc thu thập, xử lý số liệu vệ tinh và sử dụng số liệu vệ tinh để đánh giá kết quả dự báo sóng từ mô hình SWAN cho vùng biển Việt Nam được phân tích đánh giá. Thành công của nghiên cứu sẽ giúp các dự báo viên có thêm một nguồn số và công cụ phục vụ dự báo và đánh giá chất lượng dự báo sóng biển.

\section{Phương pháp nghiên cứu}

\subsection{Phương pháp quan trắc sóng bằng vệ tinh}

Nguồn số liệu quan trắc sóng bằng vệ tinh mà CMEMS cung cấp được thực hiện bởi 07 vệ tinh đo cao bao gồm Jason-3 (J3), Sentinel-3A (S3A), Sentinel-3B (S3B), Cryosat-2 (C2), SARAL / AltiKa (Al), CFOSAT (CFO) và Hai Yang-2B $(\mathrm{H} 2 \mathrm{~B})$ với các nhiệm vụ khác nhau xung quannh trái đất trong đó có vùng biển Việt Nam [17]. Hình ảnh của 07 vệ tịnh trên không gian được thể hiện như trên Hình 1 . Trong quá trình di chuyển xung quanh trái đất theo quỹ đạo của mình, các vệ tinh đo cao gửi đi một tín hiệu radar hình cầu theo hướng thiên để (the nadir). Các tín hiệu này bị phản xạ bởi bề mặt biển và quay trở lại vệ tinh. Việc phân tích tín hiệu trả về cho phép tính toán thời gian cần thiết để tín hiệu đi và trở lại, tức là khoảng cách giữa vệ tinh và bề mặt biển. Sự phân bố độ cao trạng thái bề mặt biển ảnh hưởng đến tốc độ mà tín hiệu được trả lại đầy đủ cho vệ tinh. Do vậy, độ cao sóng có nghĩa trên mặt biển được xác định từ độ dốc của mặt trước front sóng. Độ cao sóng càng cao thì tín hiệu nhận được càng trải dài theo thời gian. Độ trễ giữa lần quay lại đầu tiên và lần trả lại tín hiệu đầy đủ sẽ dẫn đến một vùng tối chứa hình dạng của sóng, chính vùng tối này sẽ chỉ ra trạng thái của độ cao mặt biển (Hình 2 và Hình 3 ).

Hệ số khuyếch tán ngược ( $\sigma_{0}$ trong Hình 2 ) có thể chịu tác động bởi tốc độ gió. Các thuật toán khác nhau đã được phát triển để giải quyết mối quan hệ giữa tốc độ gió, hệ số khuyếnh tán ngược trên bề mặt biển và cuối cùng là độ cao sóng có nghĩa. Tốc độ gió thường được đánh giá ở độ cao 10 mét so với mặt biển [17]. 


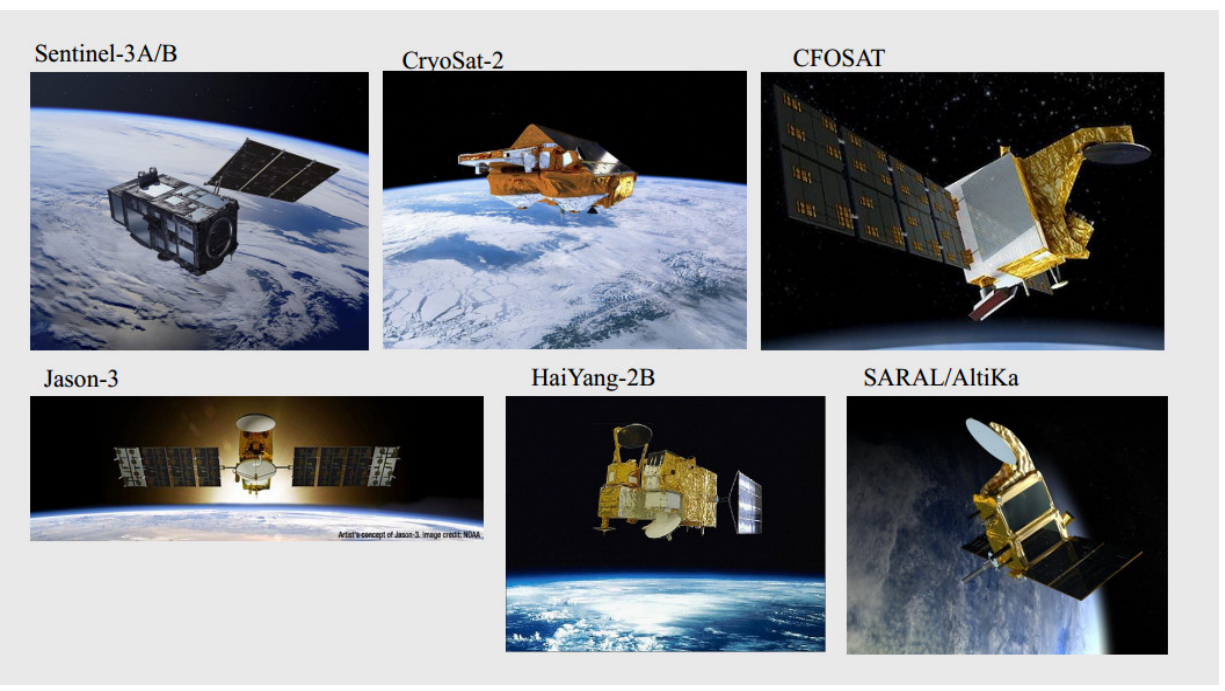

Hình 1. Hình ảnh 07 vệ tinh thực hiện quan trắc sóng trên Biển Đông của Dịch vụ Giám sát Môi trường Biển Copernicus-CMEMS [17].

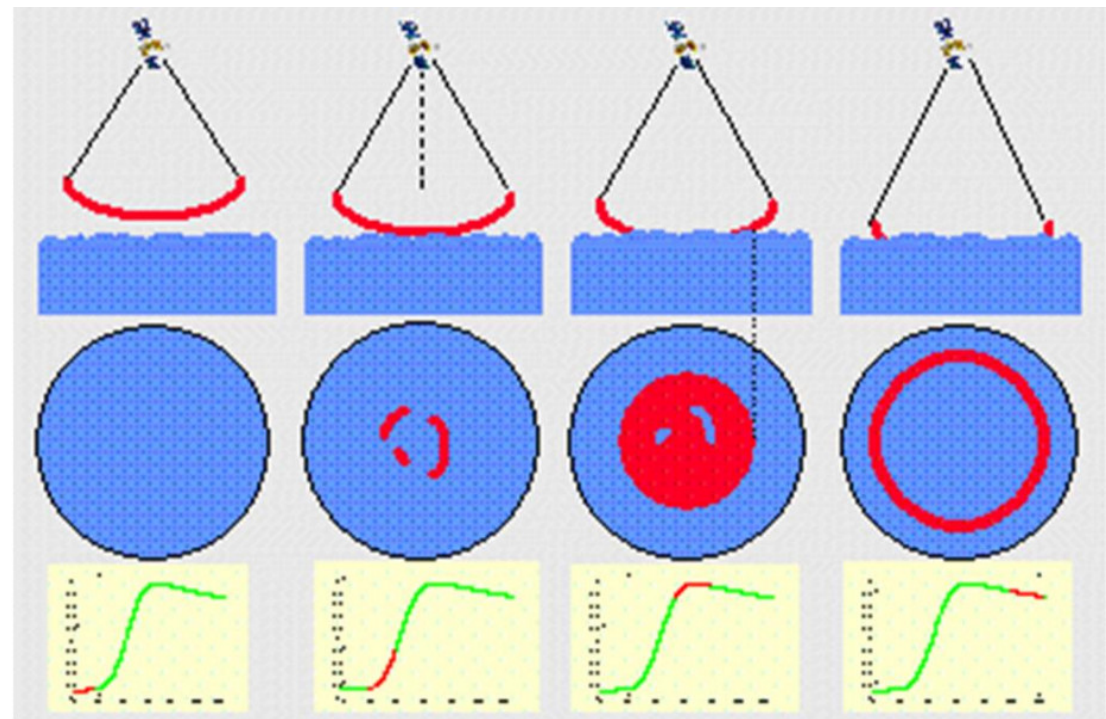

Hình 2. Dạng hình ảnh phản xạ của độ cao sóng trên bề mặt biển với phép đo cao thông thường.

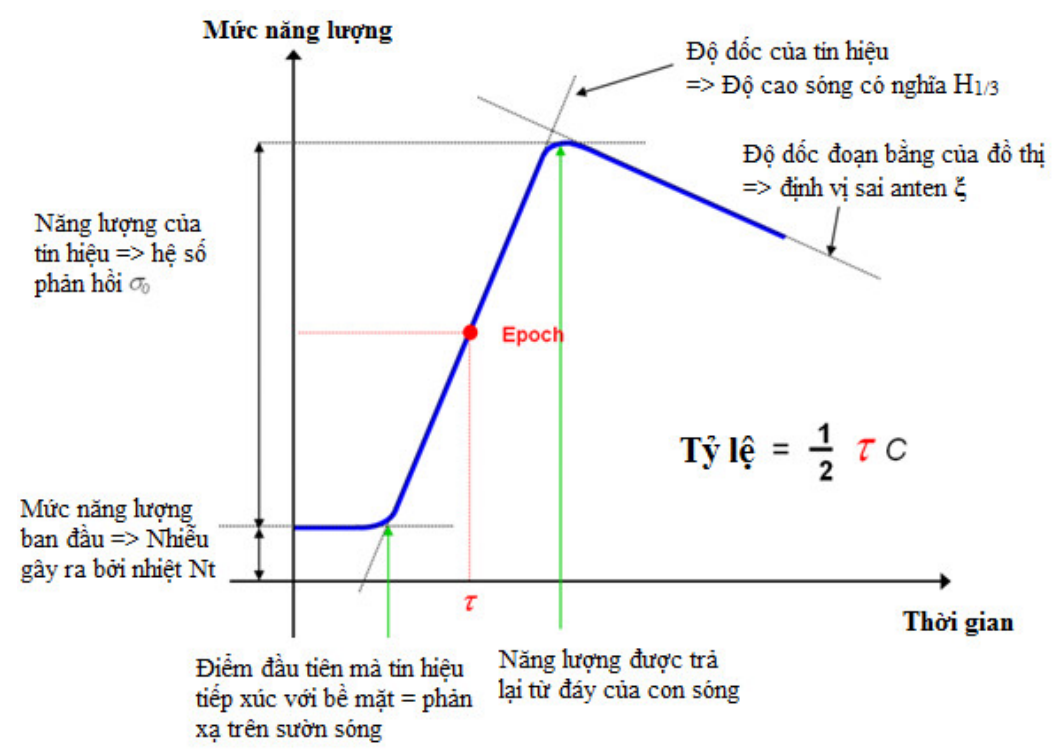

Hình 3. Cao kế của dạng sóng. 


\subsection{Nguồn số liệu}

Số liệu quan trắc độ cao sóng từ vệ tinh CFOSAT (CFO) trong tháng 10 năm 2021 được sử dụng để đánh giá kết quả dự báo độ cao sóng từ mô hình SWAN. Trong đó, số liệu vệ tinh CFOSAT (CFO) thu thập từ máy chủ Copernicus với tên sản phẩm là WAVE_GLO_WAV_L3_SWH_NRT_OBSERVATIONS_014_001. Số liệu quan trắc sóng của vệ tịnh CFO là sản phẩm của vệ tînh đo cao đã được xử lý ở cấp độ 3 (level 3 ), độ phân giải không gian $7 \mathrm{~km} \times 7 \mathrm{~km}$. Mô tả chi tiết về sản phẩm được cung cấp trên trang web của Copernicus[16-17]. SWAN là mô hình dự báo sóng thế hệ ba, dựa trên tính phổ sóng hai chiều bằng cách giải phương trình cân bằng tác động sóng (trong trường hợp không có dòng chảy có thể dùng phương trình cân bằng năng lượng sóng) có tính tới sự lan truyền sóng từ vùng nước sâu vào vùng nước nông ven bờ, đồng thời trao đổi năng lượng với gió thông qua hàm nguồn cùng vớisự tiêu tán năng lượng sóng. Cơ sở lý thuyết của mô hình SWAN được trình bày rất chi tiết trong các nghiên cứu [5-6,18]. Mô hình SWAN được thiết lập chạy nghiệp vụ tại Trung tâm Dự báo KTTV quốc gia với vùng dự báo là khu vực Biển Đông $(0-$ $\left.25^{\circ} \mathrm{N}, 95-125^{\circ} \mathrm{E}\right)$, độ phân giải ngang của mô hình là $4 \mathrm{~km} \times 4 \mathrm{~km}$, ngày chạy hai lượt với số liệu đầu vào tại các thời diểm 00 và 12 giờ UTC. Mô hình SWAN chạy với trường gió đầu vào từ mô hình IFS được cung cấp bởi Trung tâm Hạn vừa Châu Âu (European Centre for Medium-Range Weather Forecasts (ECMWF)) có độ phân giải ngang $0.2 \mathrm{~km} \times 0.2 \mathrm{~km}$.

Để có được chuỗi số liệu theo thời gian từ mô hình dự báo sóng phù hợp với các quan sát vệ tinh, một thuật toán được xây dựng để sắp xếp các điểm ảnh $\mathrm{CFO}$ với các ô lưới của mô hình (Hình 4). Ràng buộc về không gian và thời gian quyết định xem liệu một ô lưới mô hình có thể so sánh với một điểm ảnh của vệ tinh được hay không [17]. Giới hạn thời gian tập trung vào bước thời gian của mô hình và cho phép các giá trị quan trắc từ vệ tính CFO được chọn nếu chúng được ghi lại trong vòng \pm 30 phút. Theo không gian, chỉ cho phép sắp xếp vị trí các ô lưới mô hình được liên kết trực tiếp với vệ tinh với khoảng cách tối đa là $6 \mathrm{~km}$ đến điểm ảnh. Cách tiếp cận này dẫn đến hai chuỗi thời gian của các giá trị độ cao sóng, một cho mô hình sóng và một cho các quan sát vệ tinh [17].

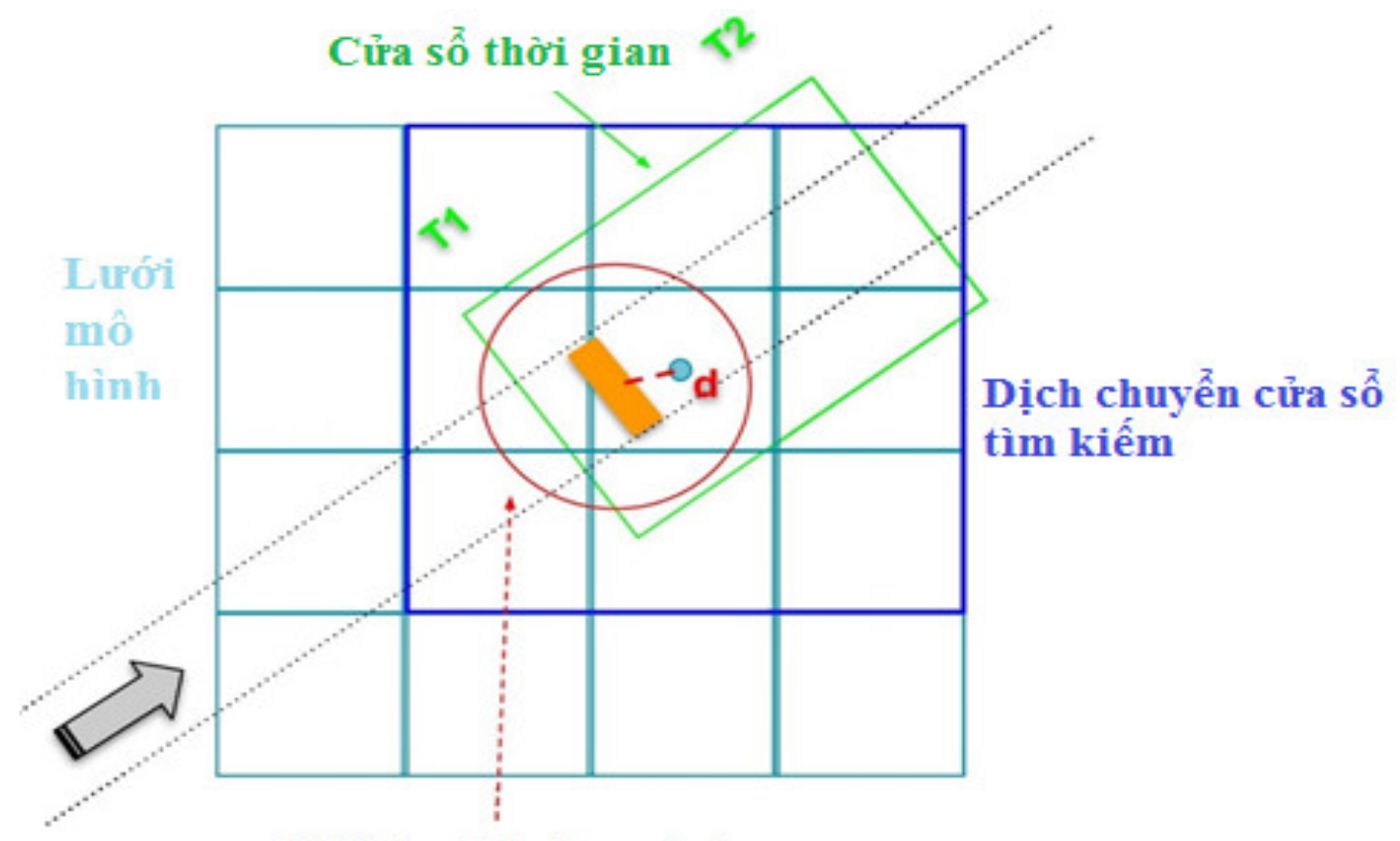

Giới hạn khoảng cách

Hình 4. Phác thảo của phương pháp sắp xếp được sử dụng (điểm ảnh của vệ tinh được minh họa bằng một hình chữ nhật màu cam). 


\subsection{Phuơng pháp đánh giá}

Để đánh giá mức độ phù hợp giữa các giá trị độ cao sóng từ mô hình với các quan sát từ vệ tinh, một số chỉ tiêu sau được đánh giá:

- Hệ số tương quan tuyến tính (Linear correlation coefficient) của n cặp giá trị $(\mathrm{x}, \mathrm{y})$ trong một tập hợp là số $\mathrm{r}$ được tính như sau:

Trong đó:

$$
r=\frac{S S_{x y}}{\sqrt{S S_{x x} \cdot S S_{y y}}}
$$

$$
\begin{gathered}
S S_{x x}=\sum x^{2}-\frac{1}{n}\left(\sum x\right)^{2} \\
S S_{x y}=\sum x y-\frac{1}{n}\left(\sum x\right)\left(\sum y\right) \\
S S_{y y}=\sum y^{2}-\frac{1}{n}\left(\sum y\right)^{2}
\end{gathered}
$$

Hệ số tương quan tuyến tính chỉ ra mức độ thay đổi của mô hình theo các giá trị quan trắc.

- Sai số trung bình (Mean Error-BIAS)

$$
B I A S=\frac{1}{N} \sum_{i=1}^{N}\left(F_{i}-O_{i}\right)
$$

Trong đó $F_{i}$ là giá trị dự báo; $O_{i}$ là giá trị quan trắc.

Chỉ số ME chỉ ra sai số trung bình so với giá trị quan trắc, nhưng không phản ánh biên độ của sai số. Giá trị dương của ME tức là trung bình giá trị dự báo lớn hơn giá trị quan trắc, giá trị âm của $\mathrm{ME}$ tương ứng với việc dự báo thấp hơn giá trị quan trắc. Chỉ số $\mathrm{ME}$ có giá trị từ đến $+\infty$, với 0 là giá trị "hoàn hảo". Tuy nhiên, đôi khi một dự báo sai lại nhận được giá trị $\mathrm{ME}=0$ khi trong đó có những sai số triệt tiêu nhau. Do vậy, nếu chỉ sử dụng một chỉ số $\mathrm{ME}$ để đánh giá chất lượng dự báo sẽ không phản ánh được độ tin cậy của kết quả dự báo.

- Sai số quân phương (Root Mean Square Error-RMSE) là căn bậc hai của MSE và là thước đo của biên độ sai số.

$$
R M S E=\sqrt{\frac{1}{N} \sum_{i=1}^{N}\left(F_{i}-O_{i}\right)^{2}}
$$

Chỉ số RMSE cho biết biên độ trung bình của sai số dự báo, nhưng không cho biết hướng của độ lệch. Các chỉ số MSE và RMSE có thể được tính toán trên bất kỳ hay tất cả các hướng theo không gian hoặc theo thời gian.

- Sai số trung bình tuyệt đối (Mean Absolute Error-MAE):

$$
M A E=\frac{1}{N} \sum_{i=1}^{N}\left|F_{i}-O_{i}\right|
$$

Chỉ số sai số tuyệt đối trung bình cho biết biên độ trung bình của sai số dự báo, nhưng không cho biết hướng của độ lệch. Giá trị 0 cho biết dự báo là "hoàn hảo". Thông thường, chỉ số MAE được sử dụng cùng với chỉ số BIAS để đưa ra ước lượng về độ tin cậy hiệu chỉnh kết quả mô phỏng của mô hình dự báo.

\section{Kết quả đánh giá dự báo độ cao sóng sử dụng số liệu quan trắc từ vệ tinh}

Trong nghiên cứu này, các kết quả dự báo từ mô hình SWAN với các thời hạn dự báo 24 và 48 giờ trong tháng 10 năm 2020 được đánh giá với số liệu quan trắc sóng bằng vệ tinh. Hình 5 là các vệt ảnh quan trắc số liệu sóng từ vệ tinh CFO trong tháng 10 năm 2020. Dựa vào số lượng điểm ảnh trong tháng 10 năm 2020 được thể hiện như trên hình 6 có thể thấy giá trị quan trắc sóng mà vệ tinh $\mathrm{CFO}$ thu thập được theo thời gian là không giống nhau, số lượng điểm ảnh phụ thuộc vào vị trí mà vệ tinh đi qua trên khu vực quan trắc. So sánh giữa các giá trị dự báo từ mô hình SWAN với số liệu quan trắc vệ tinh tại các thời điểm dự báo 24 và 48 
giờ trong tháng 10 năm 2020 được thể hiện trên các hình 7,8 và 9 cho kết quả tương đối tốt, ngoại trừ các ngày có bão (vùng khoanh tròn màu đỏ). Tháng 10 năm 2020 là tháng có khá nhiều cơn bão xảy ra liên tiếp nhau, cụ thể là các cơn Linfa (10-11/10/2020), cơn Nangka (12-15/10/2020), cơn Saudel (21-25/10/2020) và cơn Molave (26-28/10/2020), trong đó cơn Molave là cơn bão rất mạnh với cường độ bão đạt cấp 13, giật cấp 16 khi đổ bộ vào vùng biển ngoài khơi các tỉnh từ Đã Nẵng đến Bình Định [19]. Các kết quả so sánh trong tháng 10 năm 2020 cho thấy giá trị dự báo 24,48 giờ của mô hình thường thiên thấp so với quan trắc, nhưng vào thời điểm xảy ra bão mạnh giá trị dự báo lại hướng thiên cao và thường có sai số lớn.

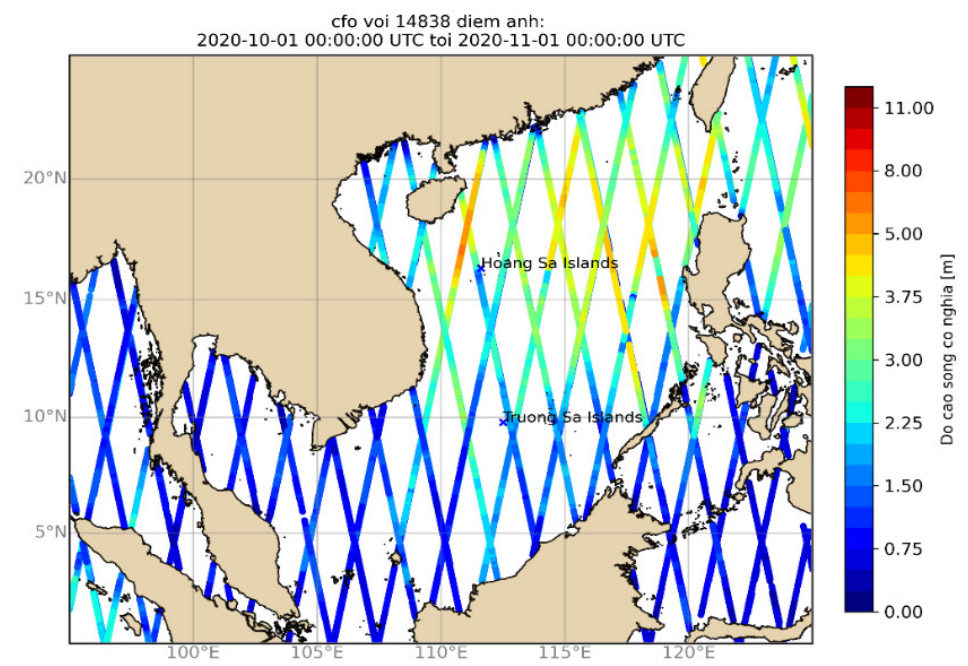

Hình 5. Quan trắc của vệ tinh $\mathrm{CFO}$ trên khu vực Biển Đông tháng 10 năm 2020.

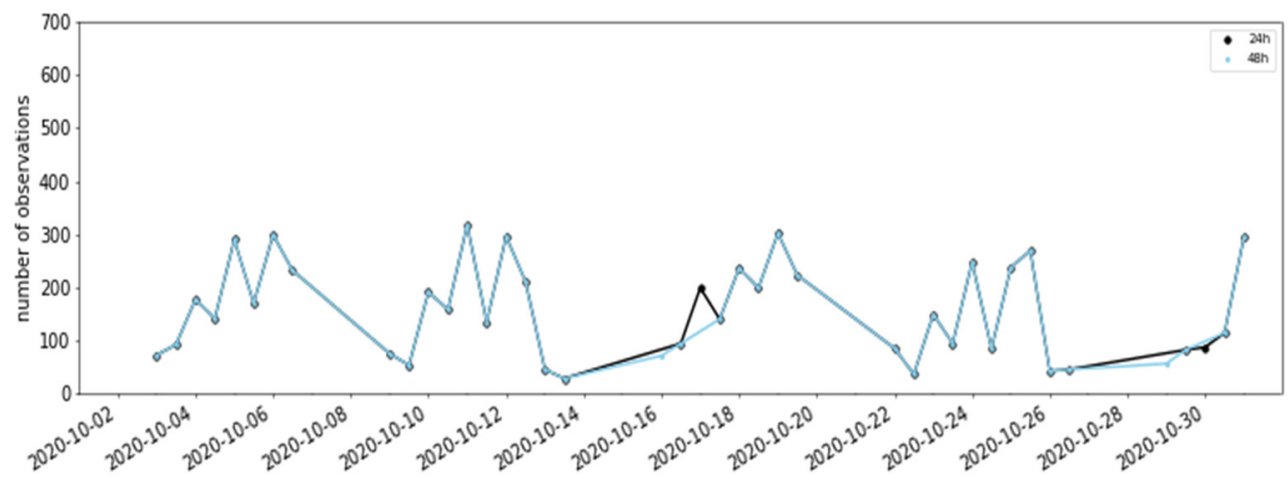

Hình 6. Số lượng điểm ảnh từ vệ tinh $\mathrm{CFO}$ thu thập được tại các bước thời gian dự báo 24 và 49 giờ trong tháng 10 năm 2020 phù hợp để so sánh với kết quả dự báo từ mô hình SWAN.
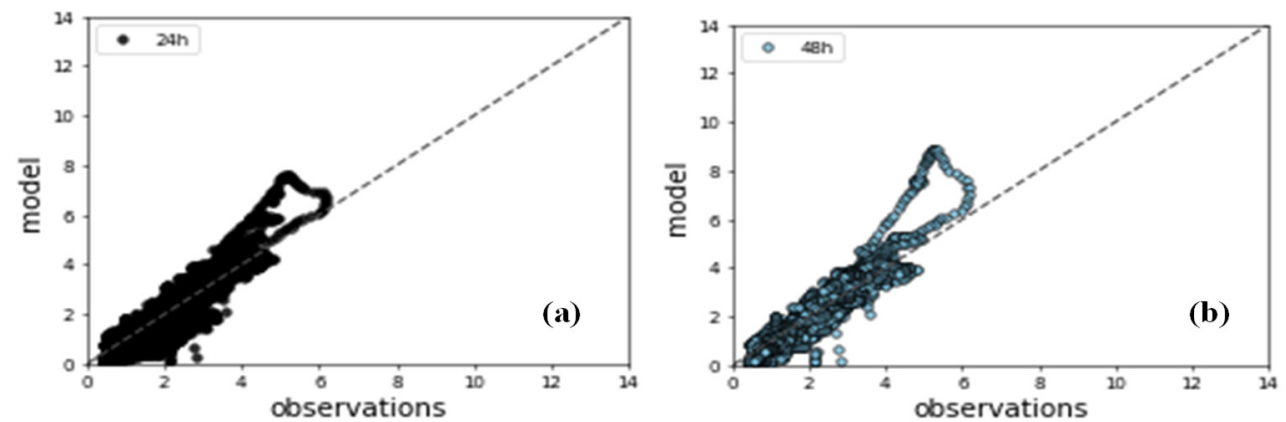

Hình 7. Biểu đồ scatter đánh giá mức độ tương quan giữa dự báo và quan trắc sóng từ vệ tinh $\mathrm{CFO}$ trên Biển Đông trong tháng 10 năm 2020 với thời hạn dự báo (a) 24 giờ và (b) 48 giờ. 


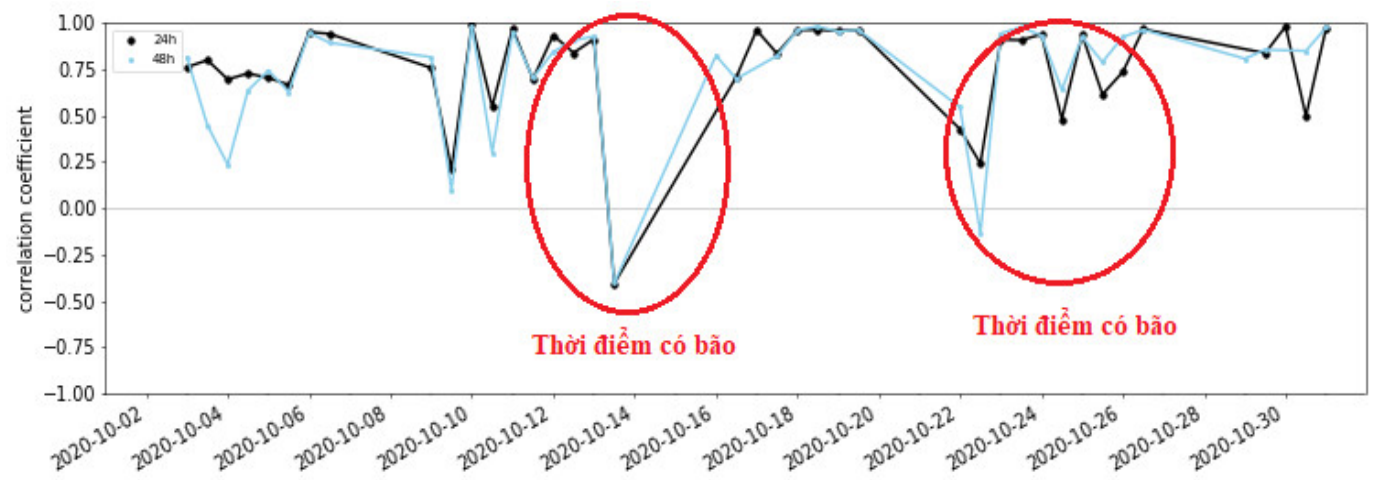

Hình 8. Hệ số tương quan giữa mô hình và quan trắc tại các thời điểm dự báo 24 và 48 giờ trong tháng 10 năm 2020 .
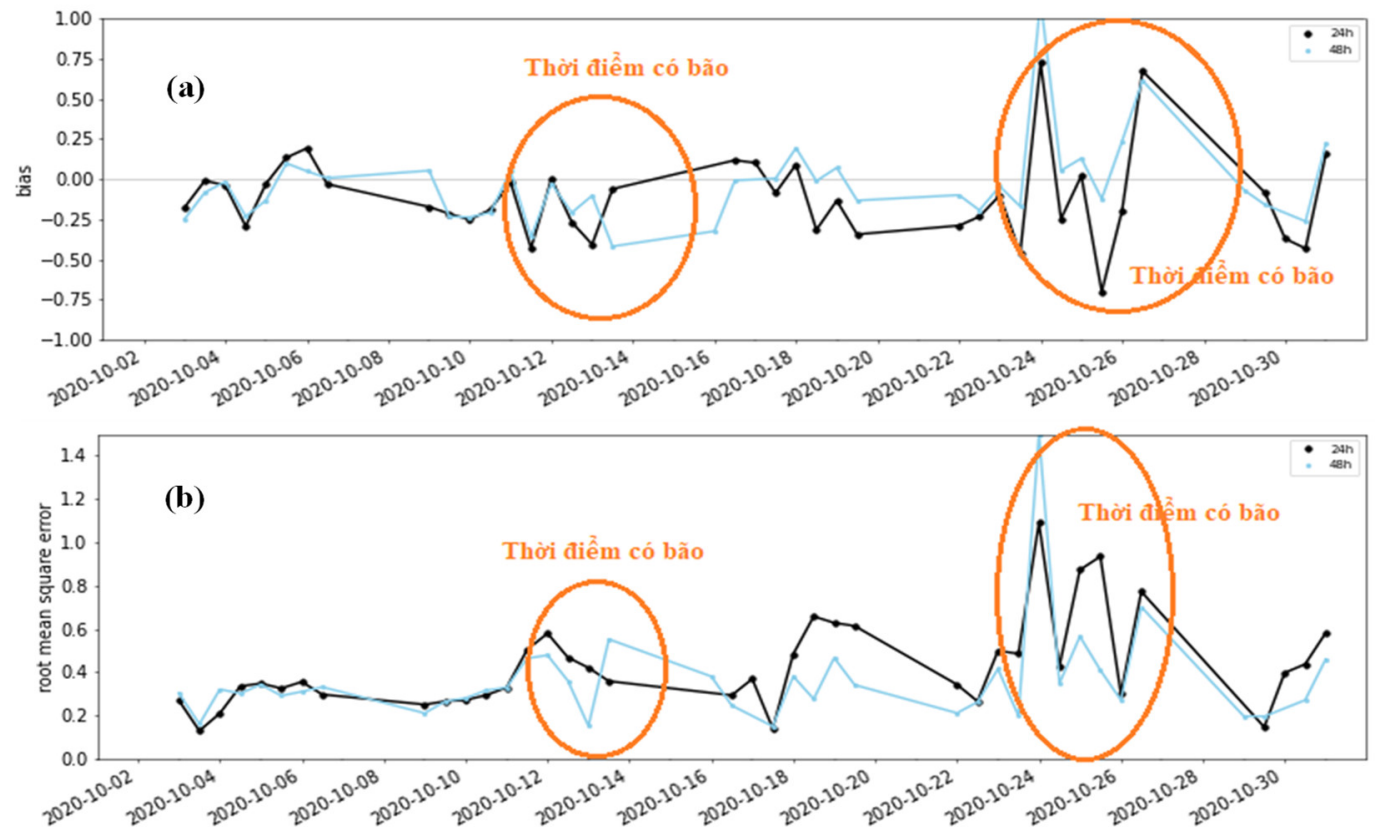

Hình 9. Sai số trung bình (BIAS) và Căn bậc hai của sai số bình phương trung bình (RMSE) giữa kết quả dự báo từ mô hình $\mathrm{SWAN}$ và số liệu quan trắc từ vệ tinh tại các thời điểm dự báo 24 và 48 giờ.

Để đánh giá cụ thể hơn, 02 trường hợp được tập trung phân tích:

- Trường hợp thứ nhất: Khoảng thời gian 00Z ngày 24/10/2020 (bão Saudel ảnh hưởng) với các thời hạn dự báo $24 \mathrm{~h}$ và $48 \mathrm{~h}$.

- Trường hợp thứ hai: Thời điểm lúc $00 Z$ ngày 10/10/2020 (thời tiết bình thường = không có bão và áp thấp nhiệt đới) với các thời hạn dự báo 24 và $48 \mathrm{~h}$.

Với trường hợp thứ nhất, tại thời điểm dự báo lúc $00 Z$ ngày $24 / 10 / 2020$ của mô hình SWAN thì vệ tinh CFO cũng cho một vệt ảnh của các giá trị quan trắc khá gần bờ và gần tâm của cơn bão trên khu vực Biển Đông. Theo hình ảnh so sánh như trên hình 10 có thể thấy giá trị quan trắc sóng nơi vệ tinh đi qua gần tâm bão nhỏ hơn so với dự báo của mô hình. Các sai số đánh giá trên Bảng 1 cũng cho thấy với 248 giá trị được đánh giá, sai số giữa mô hình và quan trắc khá lớn với sai số quân phương (RMSE), Sai số trung bình tuyệt đối (MAE) và sai số trung bình (BIAS) lần lượt là $1,09,0,85$ và 0,73 với thời hạn dự báo 24 giờ. Tại thời hạn dự báo 48 giờ các sai số này còn lớn hơn với các giá $1,50,1,12$ và 1,12 lần lượt tương ứng với RMSE, MAE và BIAS. Giá trị dương của BIAS cũng cho thấy mô hình có thiên cao hơn so với quan trắc. Mặc dù vậy, tương quan tuyến tính lại khá cao, điều này có nghĩa giá trị quan trắc và mô hình cùng có xu hướng tăng. 

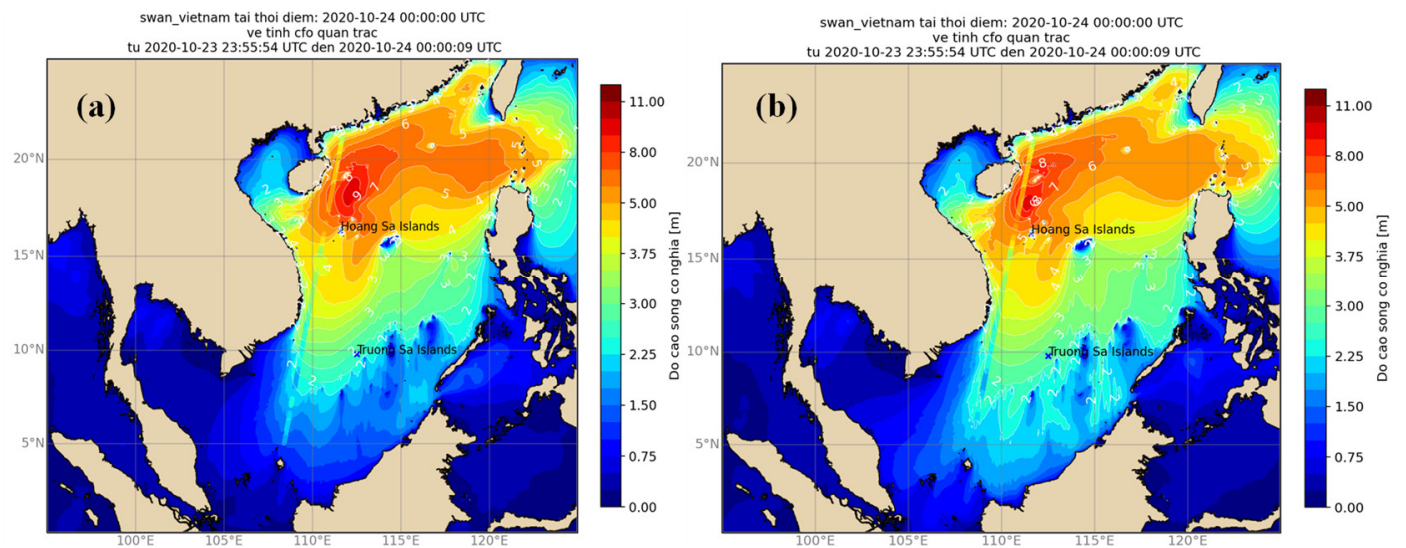

Hình 10. So sánh giữa kết quả dự báo từ mô hình $S W A N$ với quan trắc từ vệ tinh $C F O$ và trong cơn bão Saudel tại thời điểm $00 Z$ ngày 24/10/2020 với thời hạn dự báo 24 (a) và 48 giờ (b).

Bảng 1. Sai số giữa kết quả dự báo từ mô hình $\mathrm{SWAN}$ với quan trắc từ vệ tinh $\mathrm{CFO}$ tại thời điểm $00 \mathrm{Z}$ ngày 24/10/2020 với thời hạn dự báo 24 và 48 giờ.

\begin{tabular}{lcc}
\hline \multicolumn{1}{c}{ Hệ số } & \multicolumn{2}{c}{ Kết quả } \\
\cline { 2 - 3 } & 24 giờ & 48 giờ \\
\hline Tương quan tuyến tính & 0,94 & 0,93 \\
Căn bậc hai của sai số bình phương trung bình (RMSE) & 1,09 & 1,50 \\
Sai số trung bình tuyệt đối (MAE) & 0,85 & 1,12 \\
Sai số trung bình (BIAS) & 0,73 & 1,12 \\
Giá trị trung bình của mô hình & 4,21 & 4,60 \\
Giá trị trung bình của quan trắc & 3,48 & 3,48 \\
Số giá trị được đánh giá & 248 & 248 \\
\hline
\end{tabular}

Còn với trường hợp thứ hai trong điều kiện thời tiết không có bão và áp thấp nhiệt đới tại thời điểm dự báo lúc $00 Z$ ngày 10/10/2020 của mô hình SWAN, vệ tinh $C F O$ cũng đã đi qua khu vực Biển Đông và một phần vệt ảnh mà vệ tinh quan trắc được đã đi qua khu vực Vịnh Bắc Bộ. Tại thời điểm này, giữa mô hình và quan trắc đã ghi nhận được 191 giá trị độ cao sóng để so sánh. Các kết quả so sánh và đánh giá trên hình 11 và bảng 2 cho thấy mô hình dự báo khá tốt tại thời điểm này với cả hạn dự báo 24 và 48 giờ. Cụ thể, các giá trị sai số tương đối thấp như hệ số RMSE, MAE và BIAS lần lượt là $0,27,0,25$ và $-0,25$ với hạn dự báo 24 giờ và $0,28,0,24,-0,24$ với hạn dự báo 48 giờ. Các sai số giữa hạn dự báo 24 và 48 giờ có sự chênh lệch không đáng kể cho thấy dự báo xa của mô hình tại thời điểm này cũng tương đối chính xác. Hệ số BIAS mang giá trị âm cho thấy mô hình có thiên thấp hơn với quan trắc. Tương quan của cả 02 hạn dự báo gần như là tuyệt đối tại thời điểm này.

Bảng 2. Sai số kết quả dự báo từ mô hình $\mathrm{SWAN}$ với quan trắc từ vệ tinh $\mathrm{CFO}$ thời điểm $00 \mathrm{Z}$ ngày 10/10/2020 với thời hạn dự báo 24 và 48 giờ.

\begin{tabular}{lcc}
\hline \multicolumn{1}{c}{ Hệ số } & \multicolumn{2}{c}{ Kết quả } \\
\cline { 2 - 3 } & $\mathbf{2 4}$ giờ & $\mathbf{4 8}$ giờ \\
\hline Tương quan tuyến tính & 0,99 & 0,99 \\
Căn bậc hai của sai số bình phương trung bình (RMSE) & 0,27 & 0,28 \\
Sai số trung bình tuyệt đối (MAE) & 0,25 & 0,24 \\
Sai số trung bình (BIAS) & $-0,25$ & $-0,24$ \\
Giá trị trung bình của mô hình & 1,39 & 1,40 \\
\hline
\end{tabular}




\begin{tabular}{lcc}
\hline \multirow{2}{*}{ Hệ số } & \multicolumn{2}{c}{ Kết quả } \\
\cline { 2 - 3 } & $\mathbf{2 4}$ giờ & $\mathbf{4 8}$ giờ \\
\hline Giá trị trung bình của quan trắc & 1,64 & 1,64 \\
Số giá trị được đánh giá & 191 & 191 \\
\hline
\end{tabular}
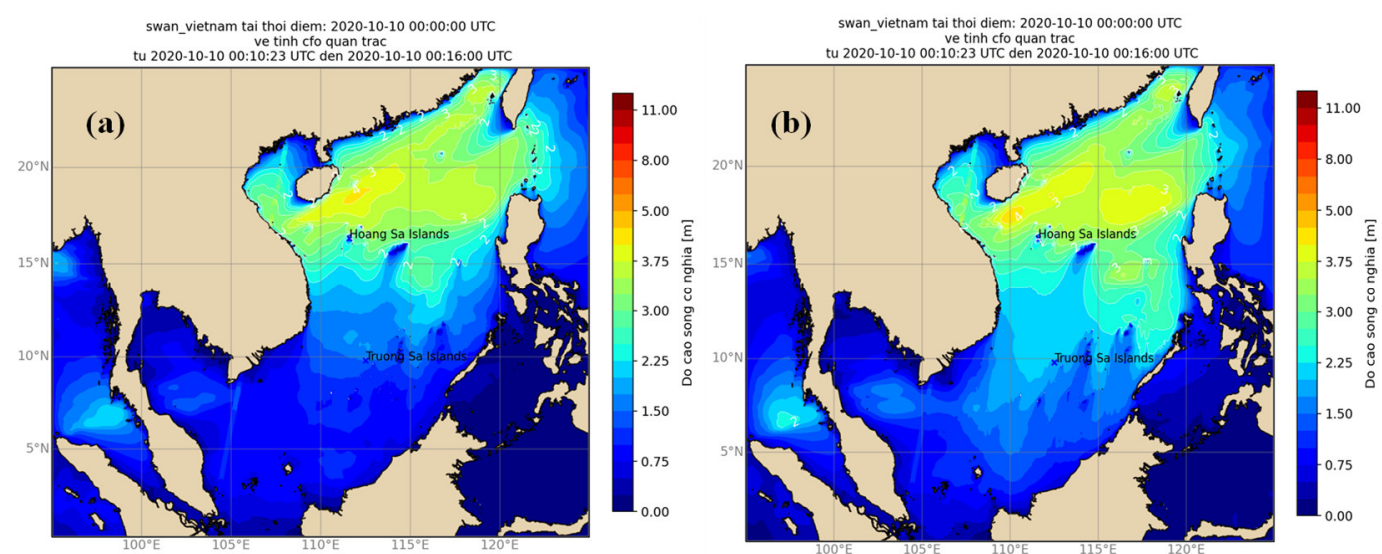

Hình 11. So sánh giữa kết quả dự báo từ mô hình $\mathrm{SWAN}$ với quan trắc từ vệ tinh $\mathrm{CFO}$ tại thời điểm $00 Z$ ngày 10/10/2020 với thời hạn dự báo 24 (a) và 48 giờ (b).

\section{Kết luận}

Trong nghiên cứu này số liệu quan trắc độ cao sóng từ vệ tinh được cung cấp bởi chương trình "Dịch vụ Giám sát Môi trường Biển Copernicus-CMEMS" được khai thác và sử dụng để đánh giá chất lượng dự báo từ mô hình $\mathrm{SWAN}$ hiện đang được thiết lập tại Trung tâm Dự báo KTTV quốc gia trong tháng 10 năm 2020. Kết quả được phân tích chi tiết tại hai thời điểm trong cơn bão Saudel lúc $00 Z$ ngày 24/10/2020 và tại một thời điểm không có bão và áp thấp nhiệt đới lúc $00 Z$ ngày 10/10/2020 với các hạn dự báo là 24 và 48 giờ. Một số kết quả đạt được tóm tắt như sau:

- Đã thu thập, phân tích và xử lý số liệu quan trắc sóng vệ tinh để phục vụ đánh giá chất lượng của mô hình dự báo sóng.

- Trong các trường hợp thử nghiệm, hệ số tương quan giữa số liệu dự báo và quan trắc từ vệ tinh độ cao sóng khá lớn đã cho thấy cùng xu thế của kết quả dự báo và quan trắc.

- So sánh giữa các giá trị dự báo từ mô hình SWAN với số liệu quan trắc vệ tinh độ cao sóng tại thời hạn dự báo 24 và 48 giờ trong tháng 10 năm 2020 cho kết quả tương đối tốt, ngoại trừ các ngày có bão. Các giá trị dự báo từ mô hình thường thiên thấp so với quan trắc, nhưng vào thời điểm có bão giá trị dự báo có thiên cao.

Những đánh giá ban đầu ở trên mới chỉ dựa vào các kết quả phân tích từ vệ tinh $\mathrm{CFO}$ trong tháng 10 năm 2020 với các quan trắc chưa bao phủ được toàn bộ miền tính và số điểm ảnh ghi nhận được tại từng thời điểm so sánh còn hạn chế. Chính vì vậy, cần thiết phải tiến hành thêm những đánh giá kết quả dự báo từ mô hình SWAN với số liệu quan trắc từ nhiều vệ tinh khác trong thời gian dài mới có thể đưa ra kết luận đầy đủ về khả năng của mô hình SWAN trong dự báo sóng biển hiện nay tại Trung tâm Dự báo KTTV quốc gia, đây cũng là những nhiệm vụ sẽ được triển khai thực hiện trong các nghiên cứu tiếp theo.

Đóng góp của tác giả: Xây dựng ý tưởng nghiên cứu: N.B.T., P.K.N.; Lựa chọn phương pháp nghiên cứu: N.B.T., P.K.N.; Xử lý số liệu: P.K.N.; Phân tích mẫu: N.B.T., P.K.N.; Lấy mẫu: P.K.N.; Viết bản thảo bài báo: N.B.T., P.K.N.; Chỉnh sửa bài báo: N.B.T., P.K.N.

Lời cảm ơn: Nghiên cứu này được tài trợ bởi đề tài nghiên cứu khoa học cấp Bộ Tài nguyên và Môi trường, mã số TNMT. 2018.05.28. Bên cạnh đó, tập thể tác giả trân trọng cảm ơn tiến sỹ Patrik Bohlinger và tiến sĩ Lark Robert Hole thuộc Viện Khí tượng Nauy đã phát triển và hỗ trợ thu thập, phân tích và xử lý dữ liệu quan trắc sóng từ vệ tinh. 
Lời cam đoan: Tập thể tác giả cam đoan bài báo này là công trình nghiên cứu của tập thể tác giả, chưa được công bố ở đâu, không được sao chép từ những nghiên cứu trước đây; không có sự tranh chấp lợi ích trong nhóm tác giả.

\section{Tài liệu tham khảo}

1. Tĩnh, Đ.N. Nghiên cứu ứng dụng số liệu vệ tinh mưa dự báo số trị kết hợp số liệu bề mặt trong dự báo lũ hệ thống sông Hồng - Thái Bình. Hà Nội: Báo cáo tổng kết đề tài nghiên cứu khoa học cấp Bộ, 2013.

2. Hải, B.T.; Sơn, L.V. Nghiên cứu ứng dụng mô hình IFAS và dữ liệu viễn thám trong mô phỏng dòng chảy lũ xuyên biên giới lưu vực sông Thao. Tạp chí Khí tương Thưy Văn 2020, 713, 24-36.

3. Kiên, N.T. Nghiên cứu ứng dụng số liệu mưa vệ tinh mô phỏng lũ khu vực trung lưu sông Mã. Tạp chí Khí twợng Thủy văn 2020, 709, 51-62.

4. Son, L.V.; Chung, L.N.; Hai, B.T.; Anh, S.H.; Quang, N.D. Assessing SatelliteBased Precipitation Products to Create Flood Forecasting in the Da River Basin, Vietnam. J. Geosci. Environ. Prot. 2019, 7(11), 113-123.

5. Tiến, T.Q.; Ngọc, P.K. Kết nối mô hình SWAN với WAM thành hệ thống dự báo sóng biển cho vùng Vịnh Bắc Bộ. Tạp chí Khí tượng thủy văn 2014, 646, 48-54.

6. Hà, B.M, Thủy, N.B., Chiến, Đ.Đ. Kết quả bước đầu dự báo sóng tổ hợp tại Việt Nam. Tạp chi Khi tuợng Thủy văn 2021, 721, 2-10.

7. Jump, K., G.J.; Cavaleri, L.; Donelan, M.; Hasselmann, K.; Hasselmann, S.; Janssen, P.A.E.M. Dynamics and modelling of ocean waves. Cambridge, UK: Cambridge University Press, 1996.

8. Stopa, J.E.; Ardhuin, F.; Girard-Ardhuin, F. Wave climate in the Arctic 1992-2014: seasonality and trends. Cryosphere 2016, 10(4), 1605-1629.

9. Bohlinger, P.; Breivik, Ø.; Economoub, T.; Müller, M. A novel approach to computing super observations for probabilistic wave model validation, Ocean Modelling, 2019, 139, 101404.

10. Jump up, Lionello, P.; Günther, H.; Janssen, P.A.E.M. Assimilation of Altimeter Data in a Global Third-Generation Wave Model. J. Geophys. Res. 1992, 97(C9), $14453-14474$.

11. Wang, J.; Aouf, L.; Jia, Y.; Zhang, Y. Validation and Calibration of Significant Wave Height and Wind Speed Retrievals from HY2B Altimeter Based on Deep Learning. Remote Sens. 2020, 12, 2858.

12. Aouf, L.; Hauser, D.; Chapron, B.; Toffoli, A.; Tourain, C.; Peureux, C. New Directional Wave Satellite Observations: Towards Improved Wave Forecasts and Climate Description in Southern Ocean. Geophys. Res. Lett. 2021, 48, e2020GL091187.

13. Smit, B.; Houghton, I.A.; Jordanova, K.; Portwood, T.; Shapiro, E.; Clark, D.; Sosa, T.T.; Janssen, M. Assimilation of significant wave height from distributed ocean wave sensors. Ocean Modell. 2021, 159, 101738.

14. https://cmems.met.no/ARC-MFC/Wave3kmValidation/2020-08/index.html

15. https://resources.marine.copernicus.eu/?option $=$ com_csw\&task $=$ results\&pk_vid $=$ fc edbf116d624c1f162014079104990a

16. https://catalogue.marine.copernicus.eu/documents/QUID/CMEMS-WAV-QUID014-001.pdf

17. https://github.com/bohlinger/wavy

18. SWAN team. Swan user manual, Delft University of Technology, 2016.

19. Đặc điểm khí tượng thủy văn năm 2020. Trung tâm Dự báo khí tượng thủy văn quốc gia, xuất bản tháng 3/2021. 


\title{
Some initial results on the application of satellite data to validate wave heights forecasting
}

\author{
Pham Khanh Ngoc $^{1 *}$, Nguyen Ba Thuy ${ }^{1}$ \\ ${ }^{1}$ National Center for Hydro-Meteorological Forecasting; ngocpkchibo@gmail.com; \\ thuybanguyen@gmail.com
}

\begin{abstract}
Improving the quality of forecasts in general and marine forecasts in particular always play an important role in hydro-meteorological warning and forecasting to best serve the prevention, response and reduction of disaster mitigation. In Vietnam, because of the limitation of marine meteorological observation data, the waves forecasting is mainly based on the results of numerical modeling. In additionally, the evaluations of the forecasting results of the model still have many limitations due to the lack of data both in terms of space and time; thus, the results of these forcast products are not really reliable enough. This study will present the use of satellite wave observation data as a reference source for forecasting as well as validating the wave forecasting in the Bien Dong sea. Validation of wave forecasting results in October 2020 shows that the forecasting and observation data have quite large correlation coefficient with the small errors at 24 and 48 hour predicting periods, except for stormy days.
\end{abstract}

Keywords: Satellite; Wave forecasting; Wave model validation. 